\title{
R Criterios
}

\section{Materiales y técnicas de dorado a través de las antiguas fuentes documentales}

Eva López Zamora, Consuelo Dalmau Moliner Facultad de Bellas Artes. U. Complutense de Madrid

\section{Resumen}

La preocupación que los antiguos artistas tenían por la duración de sus obras se revela en la cuidada elección de los materiales y la exactitud en los procedimientos, que se detecta a través del estudio de los antiguos tratados. Estos textos, expuestos de modo claro y pedagógico, pretendían transmitir los conocimientos técnicos de su época, representando una valiosa e imprescindible documentación en la formación de los artistas. En algunos casos se trata de recetarios recopilados de manera amplia y minuciosa, mientras que en otros son meras traducciones, con frecuencia, incompletas o erróneas, que deben ser interpretadas por ello con prudencia. Estos textos son testigos del pasado y guía cronológica del descubrimiento y manipulación de ciertos productos, así como de la aparición de nuevos métodos y terminologías.

Este trabajo se centra en el estudio de la técnica del dorado y los materiales que intervienen en ésta, a partir de una revisión de los textos más importantes escritos a Io largo de la Historia. 


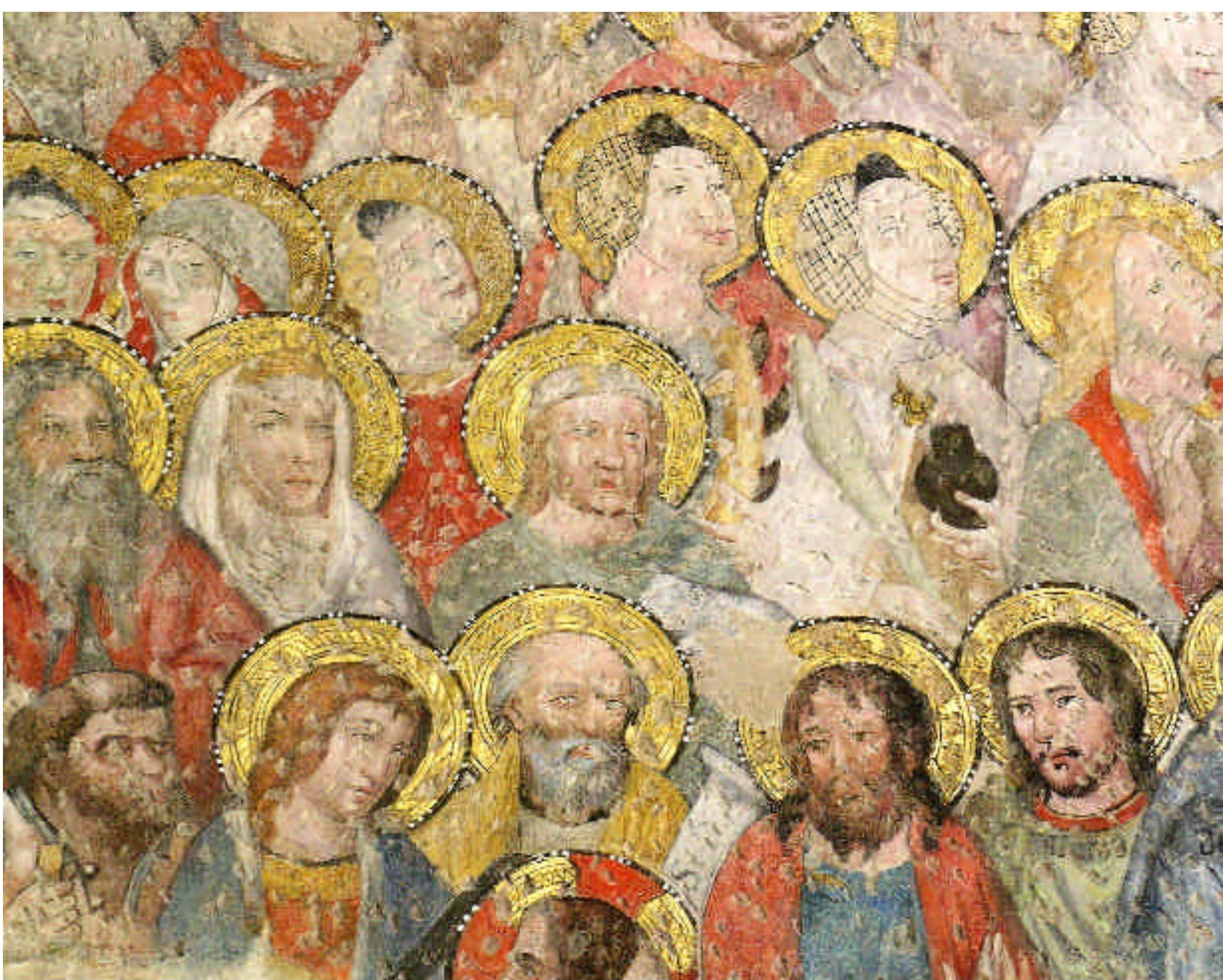

W Nimbos dorados en la pintura mural de la Capilla de San Blas (1390-1415), Gherardo

Starnina. Santa Iglesia Catedral Primada de

Toledo / Eva López Zamora 


\section{En la Edad Media, siglo VIII, se encuentra el origen de los recetarios y textos especializados en materiales y técnicas artísticas}

\section{INTRODUCCIÓN}

El gran valor atribuido al oro a lo largo de los tiempos se debe probablemente a sus cualidades -brillo, durabilidad e inalterabilidad-, así como a su escasez y dificultad de extracción. Desde la Edad de Piedra se ha usado como amuleto y ofrenda a los dioses, tal como lo atestigua su presencia en forma de joyas, brazaletes o vasijas, así como en sarcófagos y mobiliario de toda índole en civilizaciones orientales y occidentales.

De igual modo, en todas las culturas antiguas el oro, junto con la plata, se relaciona con creencias mitológicas y astrológicas. En las manifestaciones religiosas, sociales y artísticas de los distintos pueblos este metal ha tenido una estrecha relación con el concepto de luz vinculado al sol, al que se adoraba como símbolo de la divinidad. Esta valoración se mantuvo constante a lo largo del tiempo, destacando especialmente durante el gótico, donde la concepción estética concebía el espacio interno del templo como un lugar de teofanía, en el que la distribución de elementos aludía a la presencia de Dios. Apelando a esta exaltación del poder divino y terrenal, se seleccionaban aquellos materiales artísticos que así lo transmitieran al espectador. Por ello el oro tuvo de nuevo una presencia destacada en este periodo: su brillo, acentuado por la luz que penetraba a través de las vidrieras, evocaba la presencia divina.

Está igualmente reconocido el alto conocimiento de la técnica del dorado y plateado, que se desarrolla ya en las primeras dinastías egipcias y que lo aplicaron a numerosos objetos con el procedimiento tradicional al agua sobre bol de distintas tonalidades (HATCHFIELD, P; NEWMAN, R., 1991). Existen indicios, además, de que determinadas áreas de los monumentos arquitectónicos egipcios pudieron estar igualmente doradas.

A partir de la metodología empleada en pinturas murales y mosaicos en el arte bizantino, la técnica se perfecciona y alcanza su apogeo a lo largo del gótico, donde se generaliza el uso de hojas finísimas de metal (panes) que se aplican sobre preparaciones mucho más cuidadas y uniformes. Esta nueva metodología se extiende en Occidente donde se desarrollan diferentes técnicas de dorado y ornamentación sobre soportes diversos (muro, tabla, escultura, orfebrería, miniatura, textiles, pieles, etc.), así como decoraciones pintadas y grabadas con delicada maestría, que los tratadistas de la época recogen en sus escritos.

El dorado y la obtención del metal precioso, así como los procesos destinados a la decoración de pinturas y esculturas u otros tipos de obras artesanales, se han mantenido prácticamente inalterables desde sus orígenes. Estos se remontan al segundo milenio a. C., hasta llegar a nuestros días donde se siguen utilizando, si bien más ocasionalmente. En algunos casos, su evolución sólo ha afectado a la sustitución de materiales obsoletos o tóxicos ${ }^{1}$, por otros que ofreciesen mayores pres- 
taciones técnicas, persiguiéndose en última instancia el mismo fin ornamental y simbólico.

Los libros de secretos y los tratados de técnicas artísticas, junto con las Ordenanzas y otras fuentes documentales antiguas, son el testigo del conocimiento y la responsabilidad de los artistas en el desarrollo de su trabajo y aportan datos muy valiosos para la comprensión estilística y técnica de las obras, así como para su datación, conservación y restauración. A través de ellos se comprueba la importancia que la técnica de dorado tuvo dentro del conjunto de los procesos artísticos.

Los antecedentes de estos textos se podrían situar en los primeros lapidarios, manuscritos de la Grecia y Roma clásicas (siglos II a. C. al I d. C.), centrados en las propiedades de las piedras y metales. Las fuentes clásicas no compilaban recetas propiamente dichas, sino descripciones de materiales.

En la Edad Media, más concretamente en el siglo VIII y probablemente en Francia, se encuentra el origen de los recetarios y textos especializados en materiales y técnicas artísticas. Estos textos recogían inicialmente técnicas originarias del mundo griego y bizantino. Antes del año 1300 no superan en número los quince, mientras que a partir del siglo XIV y a lo largo del siglo XV, son más de cien. Su mayor auge se produjo en los siglos XVI y XVII y comienzan a decaer en el siglo XVIII.

Estos documentos son un punto de encuentro entre distintos ámbitos, artes, oficios o profesiones, en el que pintores, alquimistas, médicos y boticarios, compartían y divulgaban sus conocimientos. Sin embargo, en numerosas ocasiones, la reproducción de estas recetas y prescripciones no desencadena los resultados anunciados. Es posible que a pesar de la intención divulgativa de los textos, sus autores ocultasen intencionadamente datos, ingredientes o pasos a seguir, o bien, que al tratarse de compilaciones, recogiesen recetas incompletas y alteradas por la transmisión previa oral de su contenido o por traducciones erróneas.

A lo largo de este trabajo se enumeran algunos de los textos más relevantes para el estudio general del oro y la técnica del dorado. Se trata de una recopilación de fuentes antiguas, de los cuales se han seleccionado citas específicas a este material, manipulación y ornamentación y que pretenden constituir un índice de referencia para continuar futuras investigaciones.

En primer lugar, deben mencionarse los textos que recogen la tecnolo gía asiria y egipcia (1700-300 a. C.), como el Leyden Papyrus X, del siglo IV d. C. hallado en Tebas y escrito en Grecia, que recopila documentos de los siglos II y I a. C., el Physicia et Mystica y el Materia Medica. Por otro lado, se encuentran las primeras fuentes de la era Cristiana de PLINIO SEGUNDO (1998) y de DIOSCÓRIDES ANAZARBEO (1999), de carácter enciclopédico y sentido filosófico y teórico, escritos en el siglo I d. C.
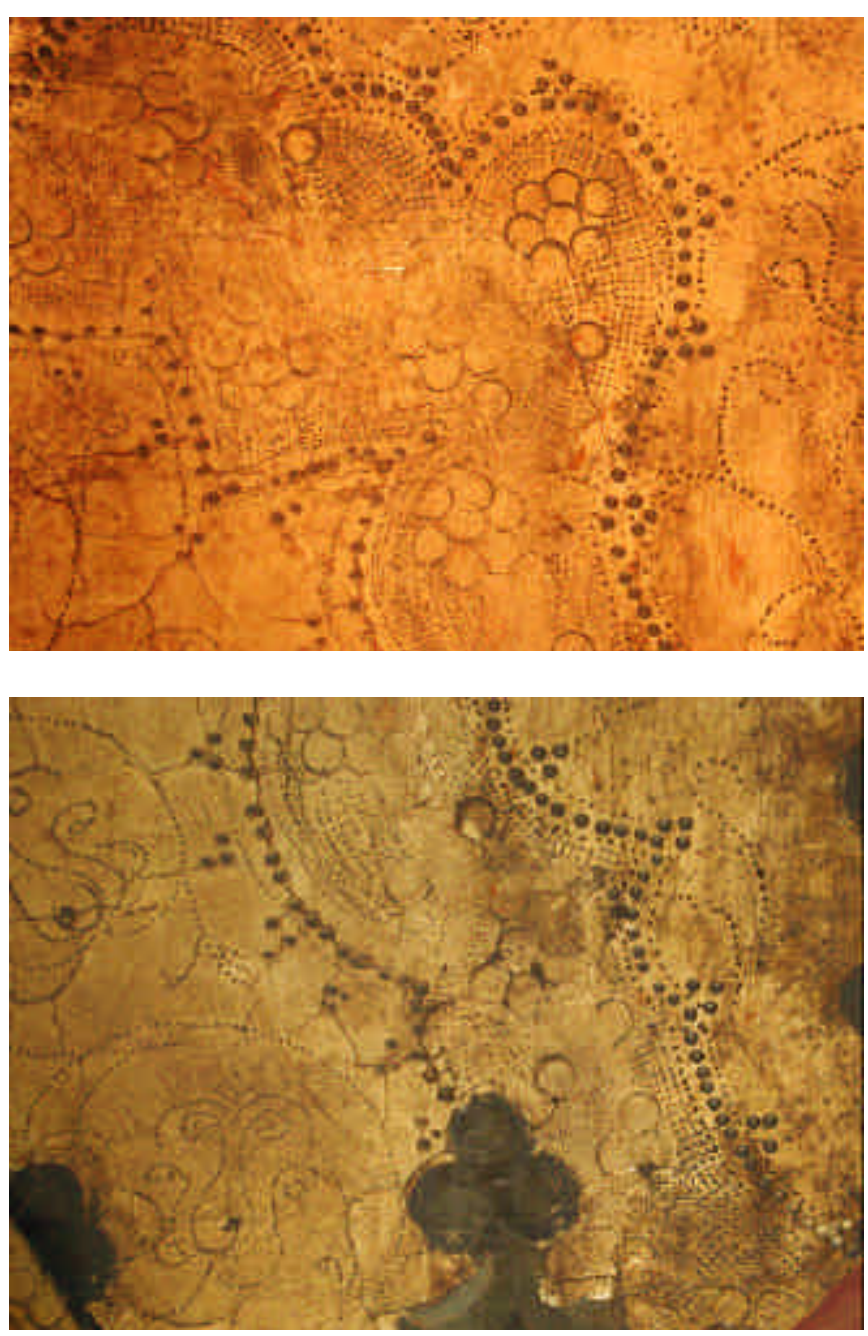

W Graneado, troquelado y repicado en el fondo dorado de la Virgen con el Niño entronizada, imponiendo la casulla a San Ildefonso (s. XIV), Maestro de Illescas. Iglesia Parroquial de Santa María de Illescas

(Toledo) / Eva López Zamora 


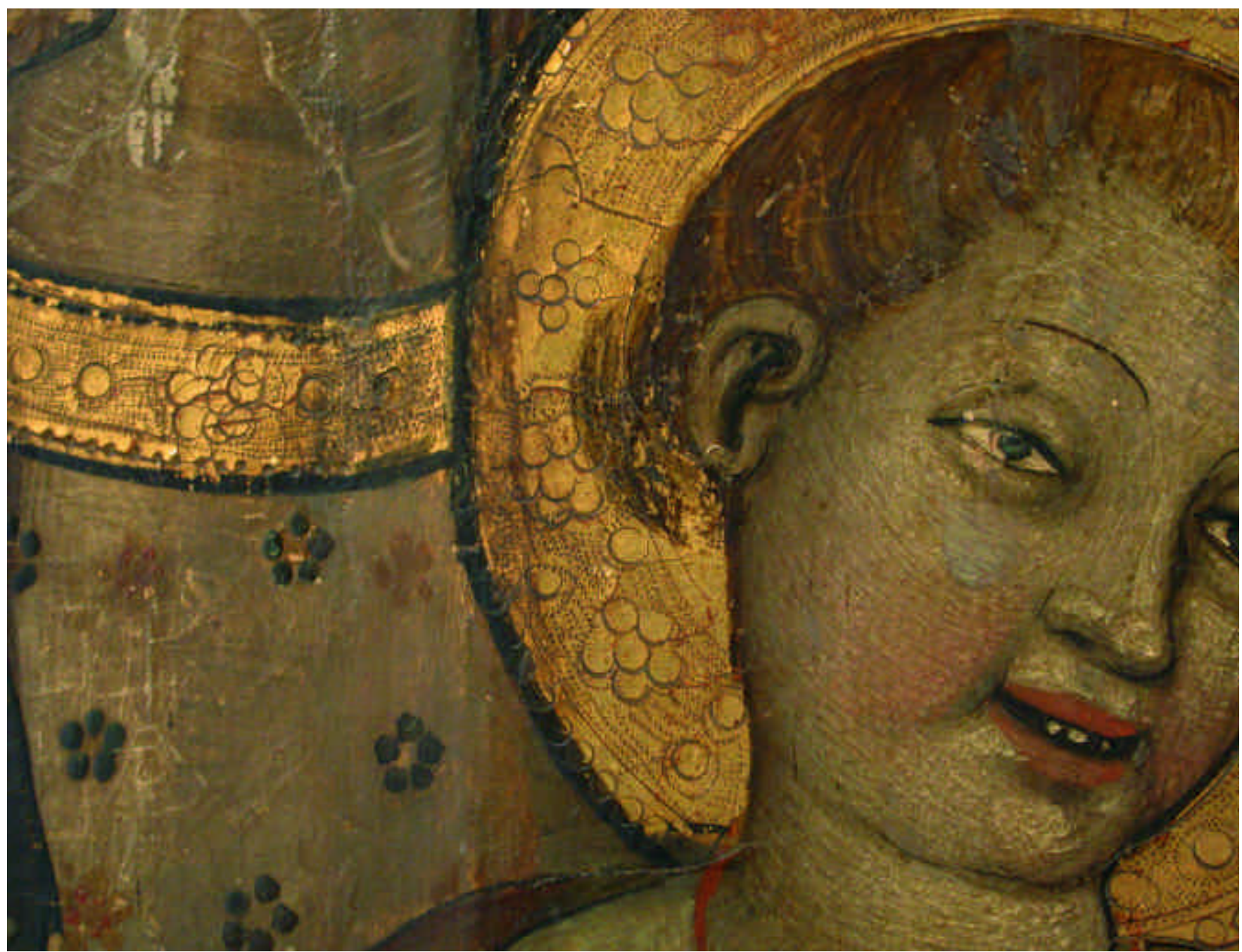

W Nimbo y cuello de vestido ornamentados con

decoraciones grabadas. Virgen con el Niño entronizada,

imponiendo la casulla a San Ildefonso (s. XIV), Maestro

de Illescas. Iglesia Parroquial de Santa María de Illescas

(Toledo) / Eva López Zamora 
Los tratados medievales, por su parte, son generalmente recopilaciones de recetas realizadas mayoritariamente por monjes en los monasterios, lugares donde se concentraba la actividad intelectual y artística. De estos se han tomado como primera referencia al oro las Etimologías de ISIDORO, ARZOBISPO DE SEVILLA (1993) del siglo VII, seguida del Manuscrito de Lucca (ANÓNIMO, 1932) del siglo VIII, el Manuscrito de Heraclio $^{2}$ HERACLIO, 1999) escrito en torno a los siglos X y XIII y el Manuscrito del monje Teófilo (HAWTHORNE; SMITH, 1979) datado entre los siglos XI y XII. Por su parte, el Mappae Clavicula (SMITH; HAWTHORNE, 1974) del siglo XII, de autor desconocido, El Lapidario de Alfonso X el Sabio (BREY MARIÑO; AMORÓS PORTOLÉZ, 1982) del siglo XIII y el Manuscrito de Audemar (AUDEMAR, 1999) de finales del siglo XIII, completan las fuentes alto-medievales.

A finales de la Edad Media y ya en el inicio del Renacimiento, estos textos adquieren un carácter de defensa de actitudes intelectuales y de ennoblecimiento de la pintura, con el empleo de metodología práctica y de gran especialización temática. Destacan en este periodo el manuscrito De arte illuminandi (ANÓNIMO, 1975), el texto islandés Líkneskjusmíð (PLAHTER, 1995), el Libro del Arte de CENNINI (1988) y el Manuscrito de Archerio (ARCHERIO, 1999)(todos ellos de finales del siglo XIV), el Manuscrito Boloñés (ANÓNIMO, 1999), anónimo del siglo XV y los textos de LE BEGUÉ (1999) y de PORTA DELLA (1589), también pertenecientes a esta centuria.

A pesar de que el uso del dorado en la pintura, tan frecuente hasta entonces, fue paulatinamente relegándose a posiciones secundarias, el conocimiento del proceso siguió mencionándose en los textos sobre la práctica artística con posterioridad a la Edad Media. Por ello, es conveniente tener en cuenta, como fuentes comparativas y consultivas de los procesos descritos en los tratados citados, los escritos pertenecientes a épocas posteriores, por las referencias que contienen a la metodología medieval o por aportar algún tipo de aclaración respecto a ella. Así por ejemplo, en el siglo XVI se encuentran el Manuscrito Marciana (ANÓNIMO, 1999) y el Manuscrito de Padua (ANÓNIMO, 1999), sin olvidar los escritos del orfebre italiano CELLINI (1989).

Las Vidas de VASARI (1998) de 1550 constituyen una valiosa fuente de información del arte italiano de los siglos XIII al XVI, mientras que BORGHINI (1969), en II Riposo, presta también atención a la técnica del dorado.

Se señalan asimismo los manuscritos del siglo XVII, que aunque son posteriores al periodo de mayor desarrollo del dorado en los fondos de tablas pintadas, son de gran interés por su relación con el tema, ya que confirman o amplían determinadas prácticas. El texto de LEBRUN (1999), conocido como Manuscrito de Bruselas y el del español PACHECO (1990), Arte de la Pintura, son ejemplos de estos tratados.

\section{A pesar del carácter divulgativo de los textos, sus autores ocultaban intencionadamente los datos o recogían recetas incompletas 0 alteradas}




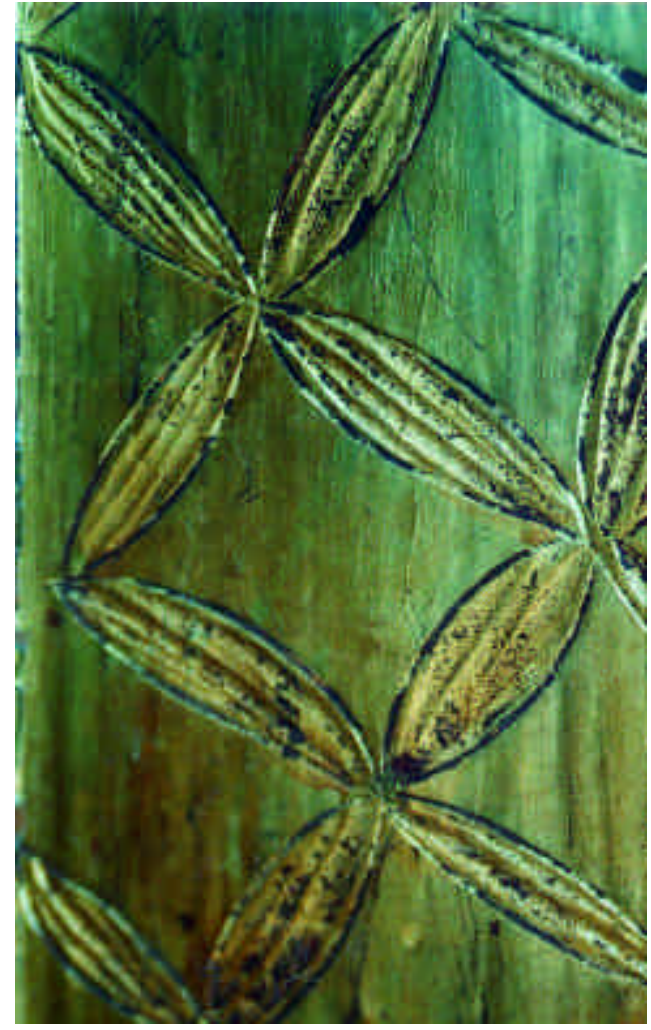

W Dibujos grabados en el aparejo, que después se han dorado. Los grabados se evidencian bajo la lámina de oro superpuesta. Retablo de Santa Ana (s. XVIII), maestro anónimo. Basílica de la Asunción de Nuestra Señora, Colmenar Viejo (Madrid) / Eva López Zamora
En este mismo sentido, el glosario de términos de pintura que PALOMINO DE CASTRO Y VELASCO (1988) incluye en EI Museo Pictórico y Escala Óptica, escrito ya en el XVIII, es de gran utilidad para la comprensión de algunos términos implicados en el dorado.

Mención aparte merecen los textos que recogen la tecnología rusa de dorado de iconos, que fue más completa y variada que la aplicada en las obras occidentales. Entre estos textos destacan las indicaciones hechas respecto a la elaboración de iconos en el Concilio de Stoglav de 1554, en el denominado Libro de los Cien Capítulos, o el manual de pintura recopilado por DIONISIUS DI FOURNA (1988) en el siglo XVIII, a partir del texto anónimo Hermeneia.

Por último destaca ya en el siglo XIX la recopilación y revisión de los tratados y manuscritos de épocas anteriores, especialmente medievales, llevada a cabo por M. P. MERRIFIELD (1999) entre 1804 y 1889, cuya aportación es de especial importancia al ordenar y traducir estos textos.

Hay que señalar que el mayor trabajo documental sobre tratados de técnicas pictóricas se inicia durante el siglo XIX y continúa a principios del siglo XX, trabajo que se paraliza a partir de 1950. La misma situación se observa en la revisión de las ordenanzas de gremios de pintores europeos. Recientemente se detecta un resurgir en el interés por el estudio de los antiguos tratados, publicándose periódicamente trabajos puntuales sobre este tema (BÁEZ AGLIO; SAN ANDRÉS MOYA, 2001) (SANTOS GÓMEZ; SAN ANDRÉS MOYA, 2001).

\section{CARACTERIZACIÓN DEL OROEN LOS TRATADOS}

El oro, sus características y los métodos de extracción, figuran citados en numerosos textos, como por ejemplo, en el Papyrus de Turín (el mapa geológico más antiguo conocido), que señala ya localizaciones de minas con depósitos de oro a lo largo del Mar Rojo (HATCHFIELD; NEWMAN, 1991: 29)

El primer texto importante de la era Cristiana relacionado con la praxis de la pintura que menciona este metal y su utilización artística lo constituye Naturalis Historia, Libri triginta septem de Plinio. En el libro trigésimo tercero, titulado Naturaleza de los Metales, se describen varias maneras de extraer el oro, la plata y el electro ${ }^{3}$ de las entrañas de la tierra; igualmente señala la escasez de oro que existía en Roma, en contraposición a su abundancia en los montes de España (PLINIO SEGUNDO, 1998: 117).

Las cualidades del oro como metal aparecen ya indicadas en los antiguos tratados, como es el caso de su densidad en contraposición con la ligereza de la plata, citada en el siglo IX en el Mappae 
Clavicula (SMITH; HAWTHORNE, 1974: 56). Esta característica se sigue distinguiendo en la baja Edad Media, por ejemplo en el texto de HERACLIO (1999: 171 y 227).

Sobre el oro, sus derivaciones filológicas y sus usos, se extiende Isidoro de Sevilla en el siglo VI en las Etimologías -compendio de los conocimientos de su época-, cuyo eje principal se basa en la búsqueda del origen de las denominaciones. Menciona este autor algunas otras particularidades del metal, como son el brillo y la reflexión de la luz, los distintos tonos que presenta más o menos rojizos, y los nombres que recibe en función de estos; así como los diversos estados en los que se puede encontrar (acuñado, trabajado -en forma de vasos o figuras por ejemplo-, en bloque y también en láminas) (ISIDORO, ARZOBISPO DE SEVILLA, 1993: 301).

A principios del siglo XII escribía el monje Teófilo acerca de la procedencia de los distintos tipos de oro empleados por los orfebres y pintores medievales: oro árabe, oro español, oro de arena o enarenado, aunque sus preferencias se inclinan por el procedente de Havilah que considera como el mejor ${ }^{4}$ (ANÓNIMO, 1966: 2). Comenta que el oro más puro se obtiene al ser bañado y pulido por las aguas fluviales (HAWTHORNE; SMITH, 1979: 118-120). Este método también lo describe Plinio, que añade además el de las minas de los pozos y montes.

Alfonso X en El Lapidario considera que el oro es el metal más noble por poseer las virtudes del sol y lo asocia con el signo del zodiaco de Géminis. Destaca su peso, dureza y brillo, especialmente cuando se limpia y bruñe. Del mismo modo que Plinio, valora el hallado en España como el mejor de todos, aunque admite que se encuentra en muchas otras partes del mundo en forma de pequeñas pepitas mezcladas con la arena de los ríos. Curiosamente describe también ciertas propiedades medicinales que se le atribuían en el siglo XIII (BREY MARIÑO AMORÓS PORTOLÉZ, 1982: 21-22).

A partir de este tratado, los textos medievales se centran mayoritariamente en la descripción de la técnica del dorado y su ornamentación, abandonando las referencias al metal como material junto a la localización y tratamiento de la materia prima. Este hecho es especialmente destacado a partir del siglo XV, cuando estas cuestiones pasan a un segundo plano debido a la mayor importancia que se concede al debate artístico.

A pesar de que los tratados de técnicas pictóricas comienzan a ahondar en la especialización sobre materias, todavía se lleva a cabo una labor compilatoria de textos antiguos sobre estos temas. Esta continuidad de tratados recopilatorios de recetas antiguas parece ser la razón de que, por ejemplo, en el Manuscrito Boloñés, escrito en el siglo XV, se encuentre aún una receta en la que se afirma obtener oro del lapislázuli (ANÓNIMO, 1999: 351).

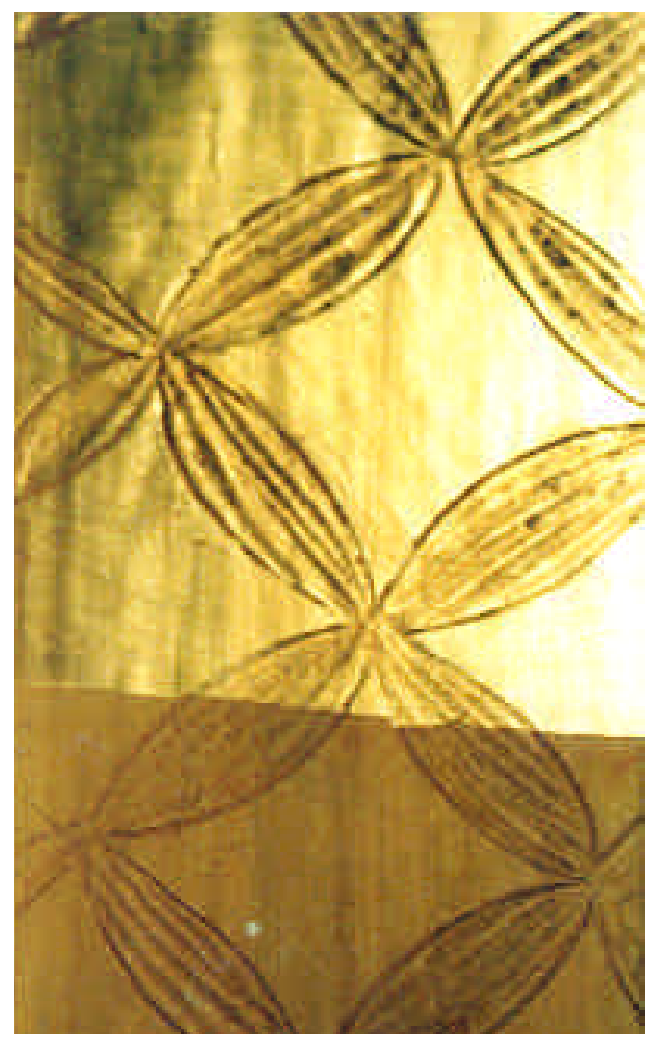

W Dibujos grabados sobre el bol cubiertos parcialmente por la lámina de oro. Retablo de Santa Ana (s. XVIII), maestro anónimo. Basílica de la Asunción de Nuestra Señora, Colmenar Viejo (Madrid) / Eva López Zamora 


\section{La escasez y alto precio del oro propiciaron que los tratadistas se preocuparan por ofrecer recetas de aleaciones con otros metales}

\section{TRATAMIENTO DEL ORO}

El oro puede encontrarse en aleación con otros metales, tales como plata o cobre. Debido a su alto coste, su aprovechamiento era un aspecto que preocupaba a quienes trabajaban con él. Por ello, en los tratados se señalan varios métodos para conocer su grado de pureza y, en su caso, la manera de poderlo separar de otros metales.

El Leyden Papyrus $X$ contiene setenta y cinco recetas relacionadas con la purificación del oro y otros metales, imitación de metales preciosos, coloreado de superficies metálicas, etc., mientras que en el Mappae Clavicula se expone una prueba para comprobar si el metal está en estado puro o se trata de una aleación de otros metales 5 . En este mismo tratado se proponen dos métodos de purificación para remover la plata y otras impurezas en forma de sulfuros por la emisión de gases sulfurosos, gracias a la aplicación de calor (SMITH; HAWTHORNE, 1974: 32 y 58)

También ARCHERIO (1999: 305) menciona el modo de purificar el oro mediante un proceso que implica ingredientes y tratamientos similares. El oro, previamente molido con sal gema se mezcla con azufre que se disuelve en agua expuesto al sol ${ }^{6}$. El monje Teófilo explica igualmente cómo se puede recuperar oro de objetos de cobre o plata dorados con aplicación de altas temperaturas (HAWTHORNE; SMITH, 1979: 71 y 147).

Las aleaciones de oro con diferentes metales han preocupado asimismo a los autores de los tratados, fundamentalmente por su escasez y elevado precio. En general, los procedimientos descritos persiguen la imitación de metales preciosos, utilizando en su lugar otros materiales menos costosos y de mayor disponibilidad para el artesano. El Mappae Clavicula, por ejemplo, es uno de los recetarios que más se ocupa de los componentes y mezclas del oro con otras materias con un carácter eminentemente químico (aunque en ocasiones se asemejen más a recetas de alquimia, prácticamente imposibles de reproducir), a modo de recordatorio para el artista. Señala abundantes combinaciones para obtener metales con apariencia de oro y describe minuciosamente distintas operaciones metalúrgicas, en las que da especial énfasis al abaratamiento de la materia prima(SMITH; HAWTHORNE, 1974:19). En menor medida se ocupa de los procesos de utilización artística y constituye una recopilación de descripciones detalladas y muestras de una tecnología anterior a la medieval.

\section{LA OBTENCIÓN DE ORO EN LÁMINAS EN LOS TRATADOS}

El desarrollo de la técnica del dorado y su aplicación en el arte alcanza su máximo apogeo en la Edad Media, especialmente en la pintura 


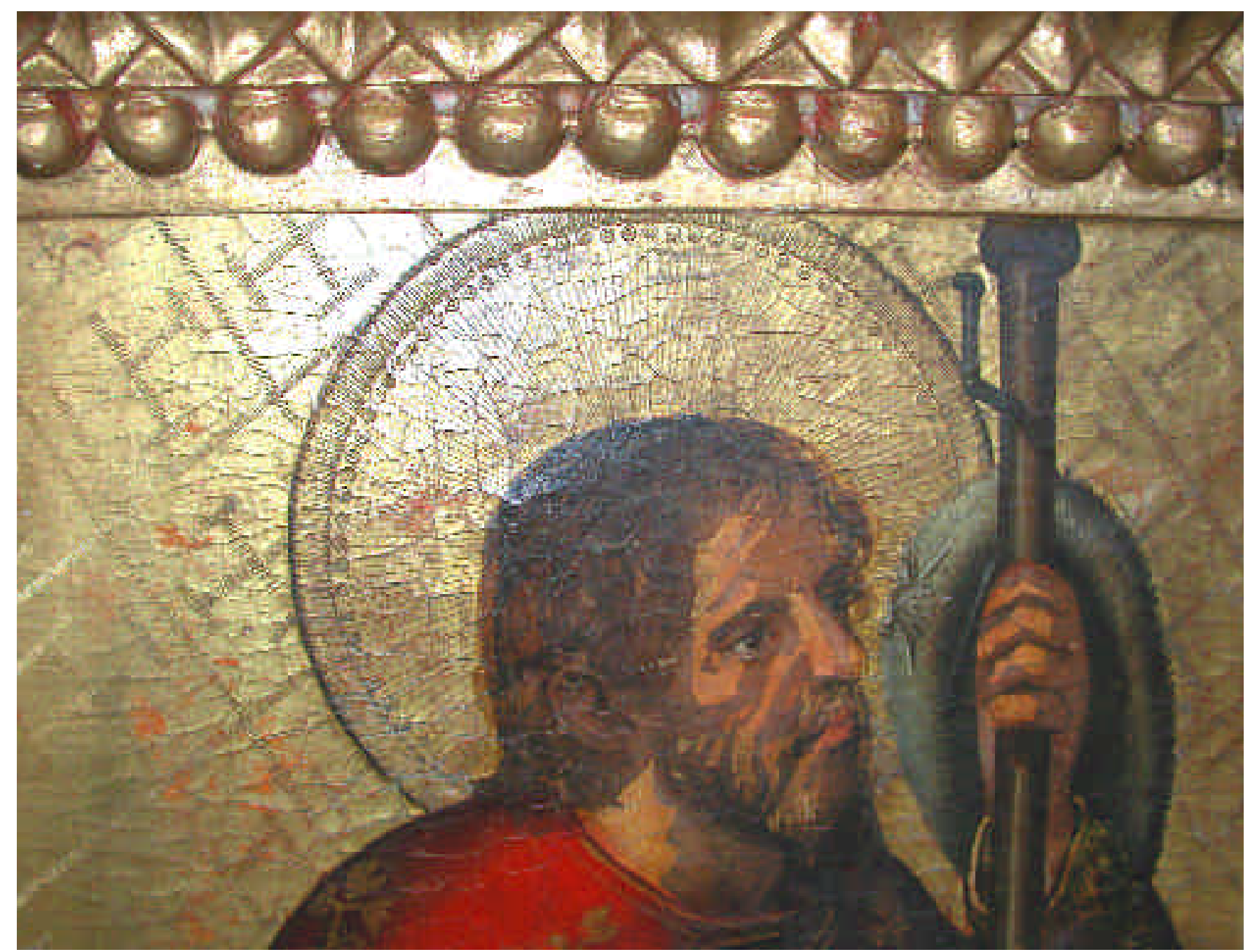

W Fondo y nimbo dorados y decorados con líneas

grabadas. Retablo de la Orden de Santiago (h. 1530),

maestro anónimo. Iglesia Parroquial de la Virgen de los

Remedios, Estremera (Madrid) / Eva López Zamora 
X Panes de oro fino / Eva López Zamora

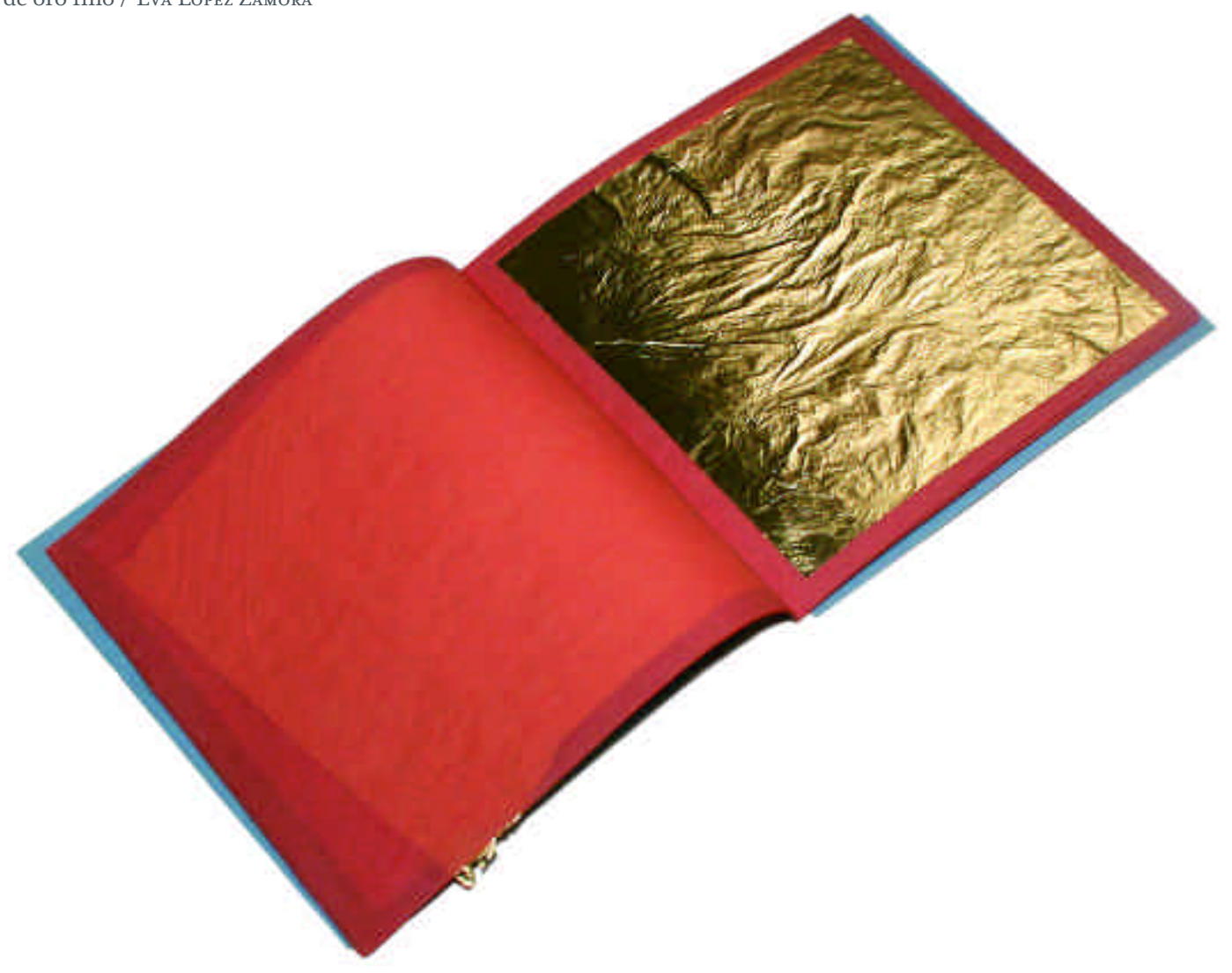

X Pan de oro fino / Eva López Zamora

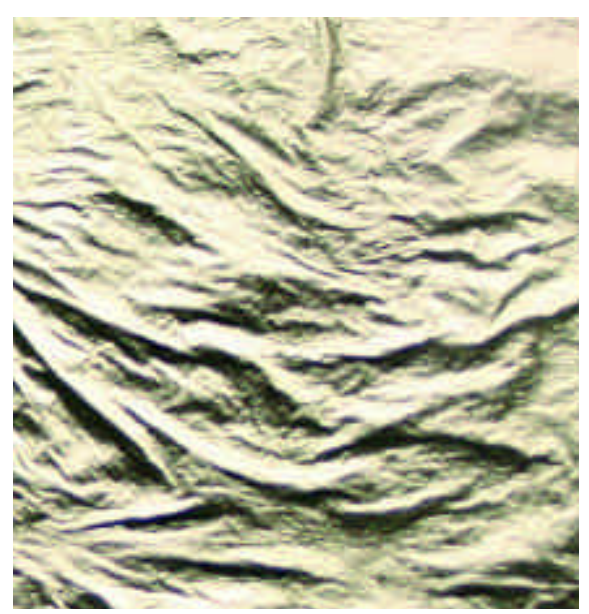

X Pan de oro falso/ Eva López Zamora

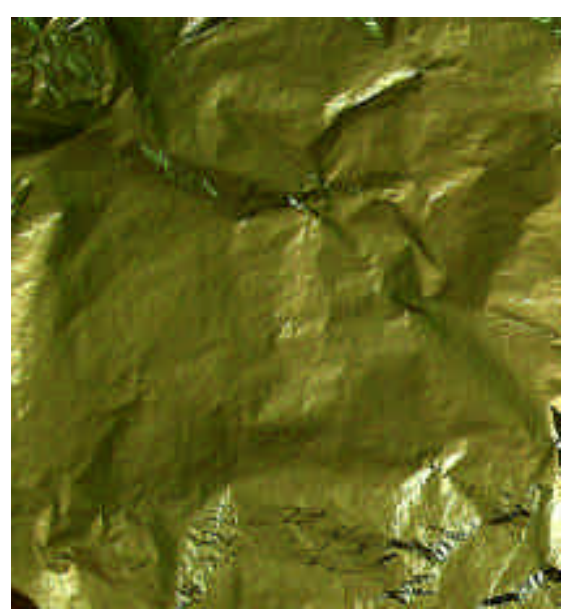

X Pan de plata / Eva López Zamora

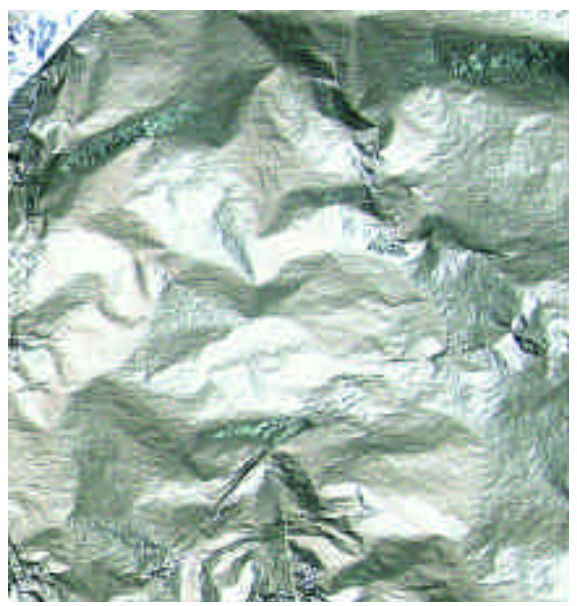


sobre tabla. Los tratados de aquella época son muestra de este conocimiento, por lo que su estudio aporta datos muy interesantes acerca del pan de oro puro y sus variedades, así como sobre las diversas tintas de este material. De igual modo, detallan la técnica de aplicación del pan de oro sobre distintos soportes y su posterior ornamentación mediante métodos tan variados como el niel, los esmaltes y estofados o las decoraciones grabadas sobre él.

Para la manipulación del oro era preciso reducirlo a finas láminas moldeables, que pudieran adaptarse a las superficies que se deseaba dorar. Esta operación que se denominaba batir era responsabilidad de los "batihojas" y se llevaba a cabo por martilleo; constaba de varias fases: afinación, laminado, y formación de panes ${ }^{7}$. Es un proceso que únicamente ha variado respecto al que llevan a cabo los batihojas en la actualidad, que no baten el oro a mano, sino con pesos de acero y en el que la pureza de los panes elaborados de este modo era de 23 quilates $^{8}$, mientras que en la actualidad la calidad del oro empleado para fabricar panes varía entre 20 y 24 quilates.

En el Mappae Clavicula (SMITH; HAWTHORNE, 1974: 65) aparece detallada la técnica de fabricación de las láminas metálicas y su aplicación sobre el soporte. Se partía inicialmente de un lingote de una onza de oro y una onza de plata que le confería un tono blanquecino, que se fundían y formaban una aleación a partes iguales de los dos metales, posteriormente se batían para obtener una hoja fina que se cortaba después en trozos cuadrados.

Sin embargo, el proceso de laminación y batido del oro no lo explica Teófilo (HAWTHORNE; SMITH, 1979:29-30), hecho que puede ser debido a que se consideraba ampliamente difundido en la Edad Media. No obstante, incorpora una novedad en su texto y es que por primera vez se menciona la preparación de un librillo hecho a partir de papiro bizantino, similar a los comercializados en la actualidad.

Posteriormente CENNINI (1988:174-175) y más tarde también VASARI (1998: 123) comentan las cualidades del pan de oro, así como sus propias preferencias respecto al lugar de adquisición o el tipo de hojas más convenientes.

Respecto al pan de oro falso, se trata de cualquier metal batido que no sea oro puro, como el estaño, la plata o el oropelp. Se consiguen así hojas que imitan el color dorado, debido a la semejanza del tono de los metales de aleación que componen estos panes falsos, o bien mediante la aplicación posterior de una tinta, corla o barniz coloreado. De los tratadistas que lo abordan destaca HERACLIO (1 999: 221 y 241), que cubre planchas de estaño con mercurio, hollín y cerveza (cervisia) y el Mappae Clavicula (SMITH; HAWTHORNE, 1974: 36 y 44), en el que las láminas de estaño se bañan en vinagre y alumbre y se cubren con una mezcla de azafrán y cola de pergamino, o bien azafrán y oropimente, mezcla a la que se puede incorporar hierbas regurgitadas o aceite de linaza y cola.

AUDEMAR (1999: 81 y 161-163) por su parte, justificándose en el elevado precio del oro, propone también el uso del azafrán que mezcla con clara de huevo para cubrir las planchas metálicas, o el jugo de corteza de ciruelo mezclado con mirra y aloe, o bien, aceites y resinas, alumbre y otras sustancias vegetales. De igual modo, LE BEGUÉ (1999: 81) explica la fabricación de planchas similares al tradicional oropel de latón, por fusión de latón, óxido de cinc y estaño.

\section{OROEN POLVO. TINTASY PURPURINAS}

Como consecuencia del elevado precio de los metales, para determinadas zonas puntuales los artistas recurrían a la aplicación de capas de color que imitaban el metal deseado. Estas capas estaban constituidas por diferentes tintas de polvo de oro (auténtico o falso), así como por pigmentos vegetales y minerales, cuya elección venía determinada por su disponibilidad en el lugar.

En el Manuscrito de Bruselas, su autor hace una distinción entre tres tipos de oro, que incluye el oro bruñido, el mate y el molido. A este último, descrito como impermeable y de fondo, lo denomina aurum contusum y lo recomienda para iluminar imágenes o para escribir con pluma (LE BRUN, 1999: 831). Palomino, sin embargo, no coincide con el nombre y afirma que proviene del latín aurum molitum o trituratum (PALOMINO DE CASTRO Y VELASCO, 1988: 671).

HERACLIO (1999: 221-241) también menciona tintas compuestas por mercurio y oro, que se podían emplear para dorar cualquier objeto, mientras que Teófilo (HAWTHORNE; SMITH, 1979: 28 y 34) relata detalladamente cómo se preparan estas tintas para decorar libros con oro y cola de pescado, comenzando por esbozar los motivos.

En el Mappae Clavicula se indican diversas maneras de fabricar tintas de ese color, con minio, arena, limaduras de oro y alumbre, además de vinagre y oropimente (posiblemente para intensificar el tono amarillo) disueltos en agua-cola. La consistencia de esta tinta es similar a una cera por lo que en el texto se señala su uso tanto en tableros como para sellar sobres. También incluye tintas en las que además de oro intervienen otros metales, como el cobre molido, plomo fundido (el oro que contiene plomo es quebradizo y de fácil molienda) o el estaño frotado con el oro, fundido y molido (SMITH; HAWTHORNE, 1974:33-35).

La utilización de tintas se mantiene en el siglo XV y el Manuscrito Boloñés (ANÓNIMO, 1999: 465-467) recoge varias de ellas muy sencillas, en las que el oro molido se mezcla con jugo vegetal o sal y miel. LE BEGUÉ (1999: 
65) sin embargo sólo cita una receta de tinte amarillo que tiene como ingrediente el oro puro, mientras que incluye varias de imitación.

Además de tintas que contienen oro en mayor o menor cantidad abundan en estos manuscritos otras fórmulas de tintas que imitan el color del metal aunque carecen de él. Del mismo modo que en el caso de las tintas de oro, el Mappae Clavicula (SMITH; HAWTHORNE, 1974 33 y 35 -37) es el recetario en el que aparecen variadas purpurinas que lo imitan. Se componen de un mayor número de ingredientes, siendo por ello su elaboración algo más compleja (jugos vegetales -mora, higuera o granada-, polvo de latón, cadmio, misy -sulfato férrico-, elidrium -sulfuro de arsénico-, resinas, clara de huevo, colas, oropimente, hiel animal, azafrán, azufre, alumbre o sandaraca). Tanto en el De arte illuminandi (ANÓNIMO, 1975: 55-59), como en el texto de LE BEGUÉ (1999: 57 y 65) y en el Manuscrito Boloñés (ANÓNIMO, 1999: 458, $460-461,465,467$ y 473-475) se proponen varias composiciones que cumplen este objetivo, en los que intervienen ingredientes similares (clara de huevo, alumbre o azufre, por ejemplo) además de mercurio, estaño o sal de amonio entre otros.

Aparecen también en estos textos antiguos varias recetas específicas para aplicar sobre diversos metales, por lo que su uso debía ser común en obras de orfebrería. Es probable que también se emplearan sobre láminas de cobre, latón, estaño, etc. HERACLIO (1999: 199) apunta la necesidad de raspar con un cuchillo las superficies metálicas que se van a cubrir con la tinta, hecho también mencionado por ARCHERIO (1999: 309), junto con la conveniencia de aplicar hiel de buey en sucesivas capas para mejorar la adhesión.

El Mappae Clavicula propone otro método basado en la aplicación de mercurio para dar color dorado a la plata y el cobre (SMITH; HAWTHOR$N E$, 1974: 40), y Le Begué, por su parte, recoge en su manuscrito dos tintas que se pueden aplicar sobre metales con el mismo fin. Éstas precisan ser calentadas al fuego en un crisol y se componen de azufre, oropimente y alumbre con orín (LE BEGUÉ, 1999: 79).

\section{EL PROCESO DE DORADO SOBRE MADERA}

La posibilidad de manipulación del oro y su transformación en finas láminas permite su aplicación sobre soportes muy variados. Sin duda la madera ofrece una de las bases más recurrentes y adecuadas para el dorado artístico, tal como se muestra en la pintura de iconos bizantinos o posteriormente en la pintura sobre tabla gótica. Especialmente en el desarrollo de esta última, el oro complementa de forma extraordinaria la policromía de las tablas pintadas. Por ello, la metodología seguida se perfeccionó a lo largo de los siglos, hecho que se pone de manifiesto por la gran variedad de recetas que se refieren a la madera dorada.
El oro es una materia versátil, que en función de diferentes adhesivos o tratamientos permite ofrecer diferentes aspectos, brillante ${ }^{10}$ o mate. El que aparece en los textos descrito con mayor frecuencia es el primero de ellos. En cambio, el dorado mate no figura señalado de manera clara hasta el siglo XVI, a pesar de que los textos anteriores a estos años recogen numerosas recetas de mordientes para esta técnica.

La calidad de un buen dorado depende en gran medida de las operacio nes preliminares y de la preparación del soporte. Por ello, los escritos de la época prestan una gran atención a esta fase del proceso y se detienen en la explicación detallada de los pasos y precauciones necesarias.

La primera precaución que se señala con respecto a estas preparaciones es la relacionada con las condiciones climatológicas, tal como se desprende de las pautas señaladas por varios tratadistas: AUDEMAR (1999: 155- 157), ARCHERIO (1 999: 263 y 265) o CEN NINI (1988: 153-156). Pero la metodología ordenada en varias capas de preparación seguida tradicionalmente y aún vigente en la actualidad (aplicación de cola animal, estratos de yeso grueso y fino, y bol), no se sigue en los primeros tratados medievales que estudian la técnica del dorado. Los estratos de preparación se simplifican en el Mappae Clavicula (SMITH, C. S; HAWTHORNE, J. G., 1974: 60) por una sencilla capa de azafrán y huevo, y múltiples variantes se exponen en los textos de AUDEMAR (1999: 153-155 y 157), ARCHERIO (1999: 259-267, 281-283 y 301-303), el Manuscrito Boloñés (ANÓNIMO, 1999: 469, 471, 473 y 477) o el Manuscrito Marciana (ANÓNIMO, 1999: 623 y 625). En el caso de preparaciones coloreadas los estratos de yeso e imprimación se unifican, pudiendo esta imprimación con color estar constituida por bol u otros materiales como el polvo de teja, por ejemplo.

En esta fase de preparación de la superficie del soporte, tienen una importancia especial los motivos en relieve y trabajos de pasta que imitaban los modos de la orfebrería y que se aplican al final del proceso preparatorio, responsables de parte de la ornamentación del oro. Todos ellos se detallan en el texto de CENNINI, autor que aporta también directrices respecto a la fase del apomazado y pulimentado en seco y en húmedo (1988: 155, 158-160) de la superficie, que más adelante recibirá la imprimación necesaria para recibir el oro.

Los adhesivos por su parte influyen igualmente en las características del dorado y en su aspecto final. Pueden ser magros, como los acuosos, o bien grasos, al incorporar aceites secantes. Así, el dorado brillante (que se obtiene al pulir el oro con un bruñidor) se realiza con adhesivos acuosos (al agua, a la templa o al guazzo) y comienza por la imprimación generalmente coloreada. De éstas el Manuscrito de Bruselas (LE BRUN, P., 1999: 831) recoge una gran variedad, compuestas por bol, sanguinaria, alumbre, bermellón, ajo, azúcar, miel, yeso, etc. La aplicación de la templa y las láminas de oro se describe de manera similar en este texto 


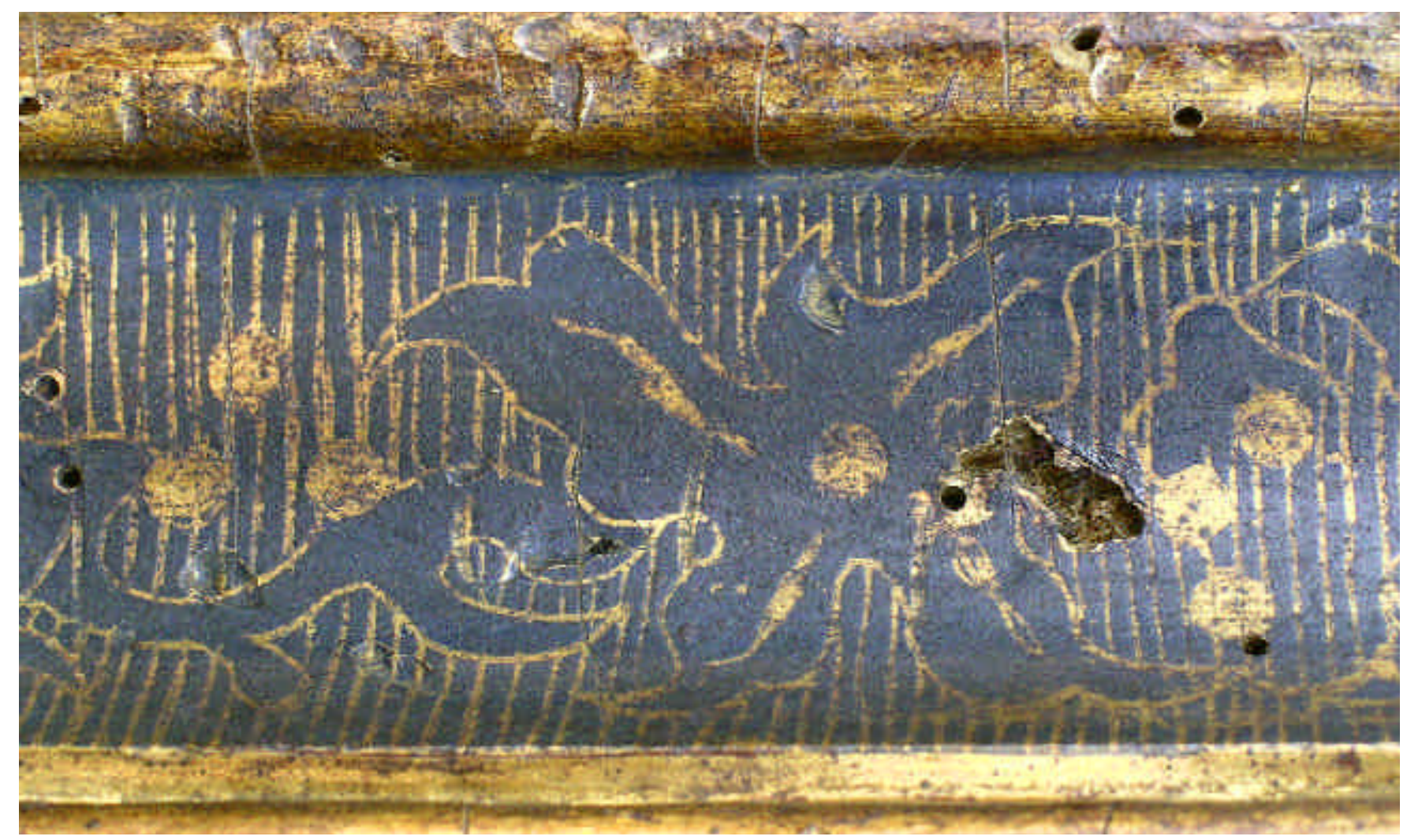

W Estofado esgrafiado realizado sobre fondo de oro. San

Miguel Arcángel (s. XV), maestro anónimo.

Ayuntamiento de Guadalajara / Eva López Zamora 


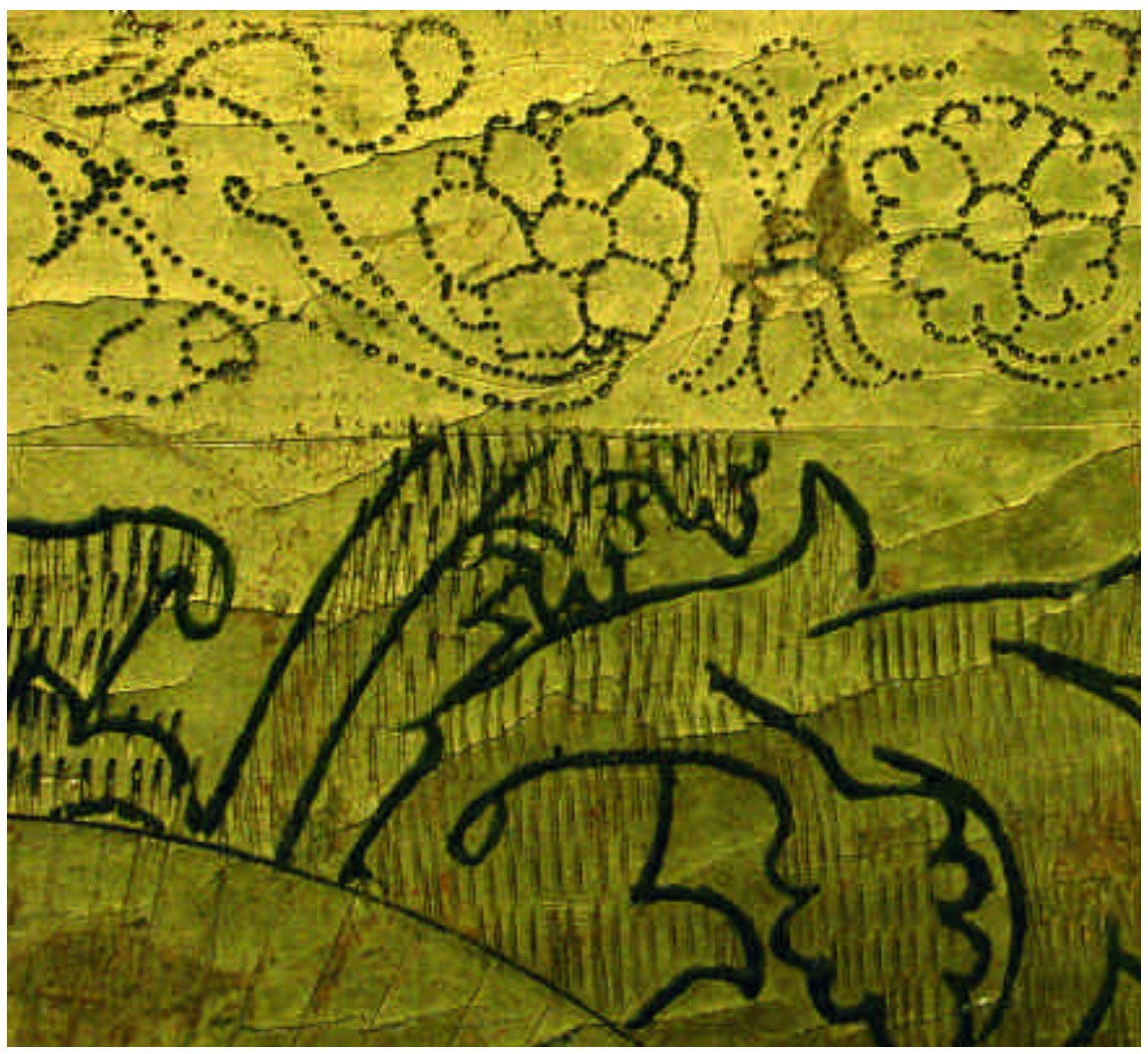

W Decoraciones con estofado a punta de pincel y punteado. Retablo de la Concepción (s. XVI), Juan de Borgoña? Santa Iglesia Catedral Primada de Toledo / Eva López Zamora

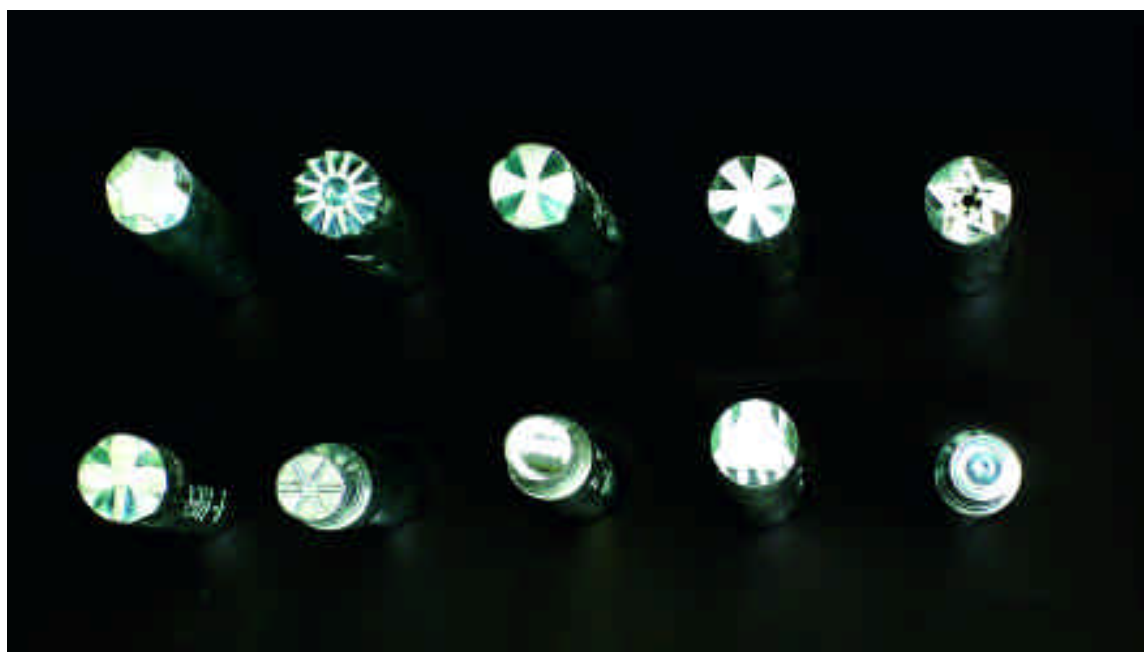

W Troqueles modernos empleados en la decoración grabada de zonas doradas en pinturas sobre tabla / Eva López Zamora 
y en el de CENNINI (1988: 169-174). Tanto este último como anteriormente Teófilo conceden gran importancia a la fabricación propia de las herramientas del taller, incluyendo instrucciones precisas para fabricar los bruñidores (HAWTHORNE; SMITH, 1979: 114).

La existencia de un dorado mate con mordiente acuoso (que se distingue del dorado brillante al suprimirse el bruñido) se menciona en el Manuscrito de Archerio (1999: 267-269), que elimina de la templa la clara de huevo (que aporta la flexibilidad necesaria para poder bruñirse) y emplea únicamente cola, asegurando erróneamente el autor que, de este modo, la superficie es más flexible.

Respecto al dorado mate de naturaleza oleosa, era menos considerado artesanalmente. Este carácter peyorativo se pone de manifiesto en las definiciones que algunos tratadistas hacen sobre él. Lo señala el Manuscrito de Bruselas (LE BRUN, P., 1999: 830 y 833) cuando lo denomina or mat o aurum impolitum, aclarando que mat proviene del griego "demente", "inepto" o "necio", debido a que no tiene brillo ni esplendor. También PALOMINO DE CASTRO Y VELASCO (1988: 575) se refiere al origen latino del aurum impolitum, aunque sin incluir ninguna consideración peyorativa adicional. La carencia de brillo de este tipo de dorado proviene precisamente de que el adhesivo graso impide el bruñido posterior.

LE BRUN alude ya específicamente a la técnica del mordiente, sisa u óleo ${ }^{11}$, que tenía la ventaja de su aplicación más sencilla y rápida (1999: 831 y 833). Autores posteriores al periodo medieval exponen las virtudes de esta técnica, como PACHECO (1990: 509), LE BEGUÉ (1999: 95), o el Manuscrito de Bruselas (LE BRUN, P., 1999: 837 y 839), entre las que destacan la resistencia a los agentes de degradación ambiental y estabilidad ante la humedad, así como la sencillez de su aplicación.

Respecto al dorado con oro falso, ya se ha mencionado cómo Teófilo describe la obtención de pan de este tipo de metal con hojas de estaño cubiertas con laca dorada, antes de su aplicación al soporte. Del mismo modo, demuestra conocer la técnica del lustrado con pintura translúci da, es decir, la aplicación del pan de estaño que una vez asentado sobre el soporte se cubre con algún tipo de mezcla para imitar oro (HAWTHORNE; SMITH, 1979: 33-34).

Los barnices para el oro falso son necesarios para compensar la ausencia de brillo. HERACLIO (1999: 225 y 241) recomienda un tipo de laca denominada auripetrum, que cumple la doble función de protección del dorado y disimula las posibles zonas de yeso visto, mientras que en el Mappae Clavicula (SMITH, C. S; HAWTHORNE, J. G., 1974: 34 y 64-65) esta operación de barnizado, sellado y suavizado del oro, se lleva a cabo con una capa de alumbre, agua, mercurio, ocre, azafrán, cola y hiel animal. El barniz del Manuscrito de Padua (ANÓNIMO, 1999: 695) se com- pone de azúcar, goma laca, aloe y aceite de linaza, y el del Manuscrito de Bruselas (LE BRUN, P., 1999: 839-840) contiene resina benzoin y azafrán. Ambas mezclas son resinosas con la ventaja de secado rápido e inalterabilidad.

Por último y a pesar de que el oro no se oxida -al contrario que la plata, que se ennegrece-, para conservar su brillo y delicadeza es preciso mantenerlo limpio de suciedad superficial y del oscurecimiento producido por el paso del tiempo, hecho que pone de manifiesto Teófilo (HAWTHORNE; SMITH, 1979: 157-158) que aconseja jabón diluido en agua para eliminar suciedades como el polvo o restos de cera, mientras que el oscurecimiento producido por el paso del tiempo lo elimina frotando el metal con un paño húmedo y polvo de carbón tamizado que se elimina después con agua. Para recobrar el brillo recomienda frotarlo con una tela y creta.

\section{EL DORADOSOBRE OTRAS MATERIAS}

Las técnicas de dorado tradicionales son susceptibles de ser ejecutadas en gran variedad de soportes, además de los paneles de madera, como atestiguan los propios autores en sus textos. Existen en los tratados explicaciones de mordientes específicos, o al menos recomendados, para estos soportes.

Así pues, aparecen diferentes consejos, métodos y materiales para dorar sobre muro. Los describe MERRIFIELD (1999: xcvi), CENNINI (1988: 139-144), o el Manuscrito Boloñés (ANÓNIMO, 1999: 465), todos ellos basados en la aplicación de mordientes resino-oleosos. Referencias para dorar pieles existen igualmente en los textos de MERRIFIELD (1999: cix-CXii), HERACLIO (1999: 239), el Mappae Clavicula (SMITH; HAWTHORNE, 1974: 66), AUDEMAR (1999: 155) o el Manuscrito de Padua (ANÓNIMO, 1999: 669) y se trata de adhesivos acuosos a base de colas animales y vegetales o clara de huevo a las que se añaden distintos pigmentos y cargas.

El dorado de los mosaicos antiguos es descrito por MERRIFIELD (1999: L y Iv-Ivii) y de manera similar en Ios textos de HERACLIO (1999: 187-189) y Mappae Clavicula (SMITH; HAWTHORNE, 1974: 48), consistente en colocar el oro sobre una pieza de vidrio o bien entre dos piezas, que se fija más tarde por fusión. Mordientes para teselas se incluyen en el Manuscrito Marciana (ANÓNIMO, 1999: 621), el de Padua (ANÓNIMO, 1999: 693) y el Boloñés (ANóNIMO, 1999: 527) en los que destaca el empleo de resinas y aceites con adición de cargas variables.

También se encuentra documentado el proceso de dorado sobre tejidos en sus múltiples variantes. En primer lugar por HERACLIO (1999: 233), el Mappae Clavicula (SMITH; HAWTHORNE, 1974: 43-44), 


\section{Los tratados, basados en el conocimiento del oficio, recogen recetas practicadas en la manipulación de metales cuya validez se ha mantenido a lo largo del tiempo}

AUDEMAR (1999: 157), LE BEGUÉ (1999: 47) y el Manuscrito Boloñés (ANÓNIMO, 1999: 463), los cuales señalan como ingrediente común las gomas vegetales, mientras que varía la adición de aceites, azafrán, alumbre, pigmentos y otros diluyentes acuosos.

Por otro lado, el gusto por dorar el papel -que alcanzó gran desarroIlo especialmente en los siglos XI al XIII y cayó en desuso en el siglo XVI- procede de Oriente, donde este material tuvo su origen, conviviendo con el dorado de pergamino y vitela. Distintos métodos de dorado sobre papel con el ingrediente común de la clara de huevo se explican en el Manuscrito Boloñés (ANÓNIMO, 1999: 461-463 y 475), en el De arte illuminandi (ANÓNIMO, 1975: 83 91, 137-141) y por LE BEGUÉ (1999: 55, 59 y 95) y el Manuscrito de Padua (ANÓNIMO, 1999: 667 y 675-677). Al huevo se le añaden gomas vegetales, azúcar, vinagre, azafrán, etc., para mejorar las propiedades del adhesivo.

Por su rareza como soporte, se refleja la sencilla receta para dorar plumas impregnadas en sal y mercurio que recoge el Manuscrito Boloñés (1999:477). Tampoco son abundantes las noticias sobre el dorado de mármoles, si bien HERACLIO (1999: 193) y el Manuscrito de Padua (1999:669-671) proporcionan ejemplos de dicho método, basados en la aplicación de un adhesivo para el oro compuesto respectivamente por vejiga de esturión o aceite cocido de nuez con litargirio, tierra amarilla y minio.

En cambio, las referencias a la técnica del dorado sobre distintos metales son muy abundantes y variadas. Una de las primeras referencias la aporta PLINIO SEGUNDO (1998: 128), seguida siglos después por el dorado con amalgama de oro y mercurio de HERACLIO (1999: 223225) y CELLINI (1989: 140-142). Heraclio propone, además, un mordiente con hollín, sal y clara de huevo, o tinta de oro diluida con mercurio, natron y vinagre. Esta receta la describe de manera casi idéntica el Mappae Clavicula (SMITH; HAWTHORNE, 1974: 36, 37 y 76), repetición por otra parte frecuente que sucede con otras recetas recogidas en ambos textos. Otro mordiente para dorar metales es la clara de huevo propuesta por LE BEGUÉ (1999: 95) y, finalmente, el dorado por la simple acción del calor que fija las láminas de oro al metal, mencionado en el Manuscrito de Bruselas (LE BRUN, 1999: 837).

\section{ORNAMENTACIÓN DE LAS LÁMINAS METÁLICAS}

El dorado, independientemente del tipo de metal, técnica o soporte utilizado, se decoraba con gran variedad de formas y técnicas. En algunos casos con diversas sustancias que se aplicaban sobre el oro para modificar su color, o bien mediante el trabajo de la superficie con diferentes herramientas, que producían determinados relieves que reflejaban la luz de forma irregular. 
En primer lugar, se destaca el nielado ${ }^{12}$, técnica recogida en numerosos tratados medievales, aplicada fundamentalmente a trabajos de orfebrería. Aunque aparece en el Manuscrito de Heraclio (HERACLIO, 1999: 243) y en el Mappae Clavicula (p. 36), es el monje Teófilo quien se ocupa pormenorizadamente de ella (HAWTHORNE; SMITH, 1979:104-105, 108 y 115). Su composición era variable, pero la formada por mercurio, cobre, plomo y azufre debió ser la más usada en la Edad Media.

Dentro del grupo de las decoraciones aplicadas sobre el oro, se pueden señalar asimismo los esmaltes conseguidos con barnices vítreos, consistentes en vidrio, sal y vinagre como principales ingredientes, cuya elaboración detallan de nuevo Teófilo (1 15 y 127-128), el Mappae Clavicula (42 y 67-68), CELLINI (1989: 41-42, 44-46 y 144-145) y VASARI (1998: 133). Con ellos se consiguen variedad de colores sobre superficies doradas, generalmente también bruñidas, o bien diferentes efectos de relieve al aplicarse sobre zonas previamente grabadas, cubriendo estos esmaltes las zonas altas y quedando doradas las partes bajas.

De igual modo se cubren los fondos dorados de las pinturas góticas sobre tabla, para modificar la coloración de ciertas áreas. Sin embargo, la decoración más interesante es la que se consigue en la superficie metálica mediante incisiones o formas grabadas con cinceles o punzones, que imitaban el repujado de la orfebrería. Estas técnicas de modulación del relieve, así como la fabricación de las herramientas necesarias para llevarlas a cabo, son objeto de especial descripción por Teófilo (HAWTHORNE, J. G; SMITH, C. S., 1979: $91-92$ y 153-154) y CENNINI (1988: 175-176). El primero de ellos hace hincapié en el repicado y punteado con pequeñas y finas marcas que proporcionan contrastes de brillo y mate, mientras que el segundo explica con detenimiento los diferentes modos de conseguir con utensilios romos marcas de mayor tamaño, como el graneado. En cuanto a los estofados esgrafiados y policromías aplicados sobre el oro en las pinturas, CENNINI es su principal descriptor (1988: 176-179). Una técnica similar la incluye también en su texto PACHECO, quien raya y graba sobre plata cubierta de una doradura para que parezca oro, haciendo que salten los colores y se vea el metal subyacente (1990: 508).

\section{CONSIDERACIONES FINALES}

El estudio del proceso del dorado a través de las antiguas fuentes documentales revela, en primer lugar, el importante papel que su materia prima principal, el oro, ha tenido desde el comienzo de las civilizaciones. Su carácter simbólico, emparentado con las distintas divinidades de los grandes imperios orientales, llevó a perfeccionar la metodología de fabricación de otros subproductos más manejables, para aplicarlos en objetos artísticos de carácter religioso y real.
La afinidad del metal precioso con las distintas creencias de estas sociedades fomentó el desarrollo de las diversas técnicas que se describen en este estudio y la transmisión de esta tecnología de unas sociedades a otras, perfeccionándose con el paso del tiempo.

Los primeros textos que mencionan el metal oro, básicamente lapidarios, lo hacen en referencia a la materia prima, su localización y métodos de extracción. Su uso artístico se inicia en la Edad Media, en principio como una técnica poco refinada y aplicaciones mayoritariamente relacionadas con la metalurgia o bien en el arte de la orfebrería. Más tarde, el dorado se depura para hacerlo susceptible de aplicar en pintura y escultura, por lo que en los tratados queda patente el paulatino perfeccionamiento de la fabricación de panes metálicos cada vez más delgados, a la vez que se amplía la gama y origen de los materiales implicados

Los tratados de técnicas artísticas consultados, cuyos autores eran en muchos casos a su vez artistas, o bien estaban en estrecho contacto con este gremio, constituyen un itinerario interpretativo de las diferentes labores llevadas a cabo por los distintos oficios implicados en la manipulación de los metales con aplicaciones artísticas.

En general, estos escritos se fundan en presupuestos heredados del pasado que surgieron con una clara función didáctica. No obstante, su lectura debe llevarse a cabo con espíritu crítico, siendo susceptibles de revisión, ya que presentan similitudes e incluso copias textuales unos de otros, omisiones voluntarias o involuntarias de recetas y detalles por parte de sus autores, así como transcripciones posteriores imprecisas. Estas circunstancias implican la posible transmisión no sólo del saber, sino también de expresiones técnicas y denominaciones confusas o erróneas. A pesar de ello, en general las recetas sobre el dorado contenidas en los tratados de técnicas artísticas se caracterizan por una mayor singularidad y originalidad, hecho que indica que se copiaban en menor medida de unos textos a otros, que en el caso de las referidas a otros materiales, por ejemplo a pigmentos.

Otro de los problemas que presenta el estudio de estas recetas es el desconocimiento de las equivalencias exactas de muchas de las unidades de medida empleadas en ellos, ya que la estandarización que se usa en la actualidad comenzó a generalizarse a principios del siglo XIX. Este hecho provoca dificultades especialmente a la hora de reproducir recetas.

A pesar de que a lo largo de los siglos se aprecia cómo las técnicas y recetas descritas se ven afectadas por pequeñas variaciones en los procesos seguidos y los materiales empleados, en líneas generales se muestra la supervivencia de la tradición, con aplicaciones siempre renovadas en aras de una mayor perdurabilidad y belleza de la obra final. 
Por todo ello, se pone de manifiesto la vigencia del estudio de la metodología seguida a través de las fuentes documentales antiguas, para comprender las particularidades en el desarrollo de las distintas técnicas artísticas. Este conocimiento puede repercutir en la mejora de las intervenciones para la conservación y restauración de las superficies doradas, a la vez que facilita la datación, comprensión estilística, iconográfica e iconológica, etc., de la variedad de manifestaciones artísticas que contienen oro como uno de sus elementos plásticos, en cualquiera de las formas descritas.

Finalmente se comprueba una vez más que los tratados, basados en el conocimiento del oficio, recogen en su mayor parte recetas ampliamente practicadas, cuya validez se ha mantenido a lo largo del tiempo, tal como se refleja en los textos posteriores. La coincidencia existente entre las prácticas indicadas en aquellos y las obras elaboradas bajo la metodología descrita se pone actualmente en evidencia, cuando se estudian éstas con los métodos de análisis modernos.

\section{Agradecimientos}

Esta investigación ha sido posible gracias a la financiación de la Universidad Complutense de Madrid, mediante la concesión de una beca FPI a Eva López Zamora. Asimismo, se desea agradecer la colaboración prestada por las siguientes instituciones, de las que se reproducen en este texto alguna de sus obras: Biblioteca Histórica "Marqués de Valdecilla" de la UCM, Santa Iglesia Catedral Primada de Toledo, Iglesia Parroquial de la Virgen de los Remedios de Estremera (Madrid), Iglesia Parroquial de Santa María de Illescas (Toledo), Basílica de la Asunción de Nuestra Señora de Colmenar Viejo (Madrid) y Ayuntamiento de Guadalajara.

\section{Notas}

${ }^{1}$ Como por ejemplo, el mercurio empleado en amalgama, que al evaporarse producía gases venenosos.

2 Según señala Merrifield, la autoría de este tratado se atribuye a un tal Heraclio, nombre de origen griego. Es posible que el autor hubiera tenido ese mismo origen o fuese nativo de Italia, del Ducado de Lombardía de Benevento, que estaba bajo la influencia griega y sarracena en la Edad Media. Sin embargo, nada se conoce de su biografía. Es probable, por otro lado, que el texto se deba a varios autores de diferentes épocas ya que no se conoce su fecha de escritura.

${ }^{3}$ Electro: del griego?'?????o? y del latin electrum. Se distinguen en los textos antiguos dos tipos de electro: uno de ellos es una clase de oro que contiene una quinta parte de plata y es de color similar al ámbar; el otro es el propio ámbar, resina fósil amarilla transparente que se halla en las orillas del mar Báltico, endurecida con el tiempo, a la que también se denomina carabe o succino. En la actualidad con este término se designa la aleación de oro blanqueado con plata que recibe el nombre de oro blanco, muy resistente a la corrosión y de apariencia plateada.

${ }^{4}$ Ciudad, situada en el noroeste de Yemen, que según el Génesis era bañada por el río Pisó

${ }^{5}$ Consiste en fundir alumbre líquido, bálsamo de Canopia y el oro que se desea analizar: la oxidación producida indica la presencia de otros metales mezclados.

${ }^{6}$ La adición de sales (alumbre, sulfato de hierro, cenizas de sosa o sal común) al fundir el metal y las aleaciones servía para fluidificar y disolver las impurezas.
${ }^{7}$ Las láminas de oro son el resultado de la reducción de lingote metálico a planchas delgadas en el laminado - fase inicial de adelgazamiento- empleadas por los orfebres como recubrimiento de otros metales. Los "panes" son hojas mucho más finas, de unas micras de grosor conseguidas al someter las láminas a la acción de la soldada y el molde, usadas no sólo por los orfebres sino además por los pintores-doradores en pinturas y esculturas. Esta diferencia en el uso de oro reducido a distintos grosores se pone de manifiesto en los tratados: los textos más antiguos mencionan mayoritariamente el uso de láminas, mientras que en los más modernos se generaliza la alusión a los panes.

${ }^{8}$ La primera referencia visual de la práctica del batido del oro para conseguir panes se encuentra en las pinturas murales de las tumbas egipcias de Re'hem en Deir el-Gabrâwi (tumba $n^{\circ}$ 72), del 2300 a. C., y en Mereruka, Saqqara, del 2323 2291 a. C

${ }^{9}$ El pan de oro falso por excelencia es el oropel, que ha recibido a lo largo de la historia distintos nombres, como pan de bronce, pan metálico o pan holandés. Es una aleación compuesta de cobre, estaño o cinc, con apariencia similar a las hojas de oro fino, pero que presenta la ventaja de su fáci manejo debido a su mayor densidad y peso. Se ha usado tradicionalmente para decorar obras en interiores no expuestas a la humedad, ya que de otro modo se oxida y ennegrece, además de ser poco estable al aire.

10 Tradicionalmente se han agrupado en función del adhesivo, es decir, dorado al agua y dorado al mordiente. Pero algunos autores basan la categorización de la técnica en el efecto final de la superficie (brillante o mate). Por tanto, proponen el término de dorado bruñido (brillante), ya que existen recetas de dorado cuyo adhesivo es acuoso $y$, sin embargo, no admite el bruñido, y dorado mate, lo que elimina cualquier ambigüedad posible.

${ }^{11}$ La técnica tradicional de dorado con aceite recibía distintos nombres:

j al mordiente, referido a cierto betún o sisa hecho de varios ingredientes para dorar. El término mordiente es erróneo desde el punto de vista actual, ya que un mordiente puede ser de naturaleza tanto aceitosa como acuosa;

j a la sisa: se identifica con aceite de linaza, recocido con algunas tierras de color, como bermellón, ocre, etc. Por tanto, sisar quiere decir preparar con la sisa lo que se va a dorar; j al óleo, que evoca el uso de aceite.

En la actualidad, todas estas denominaciones se han simplificado con el término mixtión, que significa mezcla, pero que en los tratados de técnicas no aparece, por tratarse de una denominación contemporánea. Sin embargo, sí aparecía en los tratados antiguos la denominación de tono mixto, del que podría derivar este término.

${ }^{12}$ El niel es una amalgama de diferentes sustancias fundidas de color negro, que se dispone sobre superficies claras para conseguir un efecto de contraste lumínico. Se puede aplicar sobre metales grabados, donde el tono negro queda incrustado en los surcos o a modo de dibujo superficial sobre el oro, la plata, etc,, pero siempre fijado con calor. 


\section{Bibliografía}

ANóNIMO (1932) Compositiones ad tingenda musiva, (s. VIII), ("Manuscrito de Lucca"), (Codex Lucensis 490 de la Biblioteca Capitular de Lucca), Uppsala: Almqvist \& Wiksells Boktryckeri, 1932

ANóNIMo (1966) Santa Biblia. Antiguo y Nuevo Testamento Madrid: Sociedades Bíblicas, 1966, Génesis. 2. 10- 13, p. 2

ANóNIMO (1975) De arte illuminandi. E altri trattati sulla tecnica della miniatura medievale, (segunda mitad siglo XIV), (trad. y comentarios de Franco Brunello), Vicenza: Neri Pozza Editore 1975

ANóNIMO (1999) Secreti diversi, (s. XVI), ("Manuscrito Marciana"). En MERRIFIELD, M. P. (1999) Medieval and Renaissance Treatises on the Art of Painting (1849), New York Dover, 1999, pp. 601-640

ANóNIMO (1999) Ricette per far ogni sorte di colori, (s. XVIXVII), ("Manuscrito de Padua"). En MERRIFIELD, M. P. (1999) Medieval and Renaissance Treatises on the Art of Painting, (1849), New York: Dover, 1999, pp. 641-717

ANÓNIMO (1999) Secreti per Colori, (s. XV), ("Manuscrito Boloñés") En MERRIFIELD, M. P. (1999) Medieval and Renaissance Treatises on the Art of Painting, (1849), New York: Dover, 1999 pp. 325-600

ARCHeRIO, J. (1999) De Coloribus Diversis Modis Tractatur in Sequentibus, De diversis coloribus, (s. XIV), ("Manuscrito de Archerio"). En MERRIFIELD, M. P. (1999) Medieval and Renaissance Treatises on the Art of Painting, (1849), New York Dover, 1999, pp. 258-321

AUDEMAR, P. S.(1999) Liber Magistri Petri de Sancto Audemaro de coloribus faciendis, (s. XIII), ("Manuscrito de Audemar"). En MERRIFIELD, M. P. (1999) Medieval and Renaissance Treatises on the Art of Painting, (1849), New York: Dover, 1999, pp. 112-165

BÁEZ AGLIO, Mª. I.; SAN ANDRÉS MOYA, M. (2001) La prácti ca de la pintura a través de las fuentes documentales. Boletín de Instituto Andaluz de Patrimonio Histórico, 34, 2001, pp. 64-77

BORGHINI, R. (1969) // Riposo, (1584), Georg Olms, Hildesheim, 1969
BREY MARIÑO, M; AMORÓS PORTOLÉZ, J. L. (1982) El prime Lapidario de Alfonso X El Sabio. El códice y su texto, ("El Lapidario de Alfonso X, s. XIII"), (ed. facsímil del Ms. H. I. 15 de la Biblioteca de El Escorial), 2 vols., Madrid: Edilan, 1982

CENNINI, C. (1988) El Libro del Arte, (s. XIV), Madrid: Akal, 1988

CELLINI, B. (1989) Tratados de orfebrería, escultura, dibujo y arquitectura, (s. XVI), Madrid: Akal, 1989

DIONISIUS DI FOURNA (1988) Hermeneia, (Cod. Gr. 708 de la Biblioteca Saltykov-Shechedrin de Leningrado), Londres: The Sagittarius Press, 1988

DIOSCóRIDES ANAZARBeO, P. (1999) Acerca de la Materia medicinal y de los venenos mortíferos, (s. I d. C.), (facsímil núm. 1691, ed. de 1566, Salamanca), Madrid: Doce Calles y Fundación de Ciencias de la Salud, 1999

HATCHField, P.; NEWMAN, R. (1991) Ancient Egyptian Gilding Methods. Gilded Wood. Conservation and History. Symposium Gilding Conservation, Philadelphia Museum of Art (October, 1988) Connecticut: Sound View Press, Madison, 199

HAWTHORNE, J. G.; SMITH, C. S. (1979) Theophilus. On Divers Arts. The Foremost Medieval Treatise on Painting, Glassmaking and Metalwork New York: Dover, 1979

HERACLIO (1999) De coloribus et artibus Romanorum, (s. X-XIII) ("Manuscrito de Heraclio"). En MERRIFIELD, M. P. (1999) Medievo and Renaissance Treatises on the Art of Painting, (1849), New York: Dover, 1999, pp. 166-257

ISIDORO, ARZOBISPO DE SEVILLA (1993), Etimologías, (s. VII), vol. II, libros XI-XX, $2^{a}$ ed., Madrid: Biblioteca de Autores Cristianos, Católica, 1993

LE BEGUÉ, J. (1999) Experimenta de Coloribus, (1431), ("Manuscrito de Le Begué"). En MERRIFIELD, M. P. (1999) Medieva and Renaissance Treatises on the Art of Painting, (1849), New York: Dover, 1999, pp. 1-321

LE BRUN, P. (1999) Recueil des essaies des merveilles de la peinture, (1635), ("Manuscrito de Bruselas"). En MERRIFIELD, M. P.
(1999) Medieval and Renaissance Treatises on the Art of Painting, (1849), New York: Dover, 1999, pp. 756-84

MERRIFIELD, M. P. (1999) Medieval and Renaissance Treatises on the Art of Painting (1849), New York: Dover, 1999

PACHeCo, F. (1990) El Arte de la Pintura, (1649), Madrid Cátedra, 1990

PALOMINO DE CASTRO Y VELASCO, A. (1988) El Museo Pictórico y Escala Óptica ll. Práctica de la pintura, (1715-24). (2 vols) vol. II, Madrid: Aguilar, 1988

PLAHTER, U. (1995) Líkneskjusmír, 14th-Century Instructions for painting from Iceland. Norwegian Medieval Altar Frontals and Related Materials, (Acta ad Archaeologiam et Artium Historiam Pertinentia, vol. XI), (papers for the Conference in Oslo, 16th to 19th December 1989), Institutum Romanum Norvegiae, Roma: Giorgio Bretschneider Ed., 1995, pp. 157-171

PLINIO SEGUNDO, C. (1998) Naturalis Historia. Historia natural de Cayo Plinio Segundo, (s. I d. C.), Madrid: Visor Libros, 1998

PORTA DELLA, G. B. (1589) Magiae Naturalis. Libri XX, Neopolis: apud Horatium Saluianum, Napoli, DDLXXXVIIII, 1589

SANTOS GÓMEZ, S.; SAN ANDRÉS MOYA, M. (2001) Aportaciones de antiguas Ordenanzas al estudio de las técnicas pictóricas. Pátina, Escuela Superior de Conservación y Restauración de Madrid, Septiembre, 10 y 11, 2001, pp. 266-285

SMITH, C. S; HAWTHORNE, J. G. (1974) Mappae Clavicula. Little Key to the World of Medieval Technique, (título de manuscrito original "Mappae Clavicula", s. XII). The American Philosophical Society, Year Book, New Series, 64, part 4. Philadelphia, 1974, pp. 3-122

VASARI, G. (1998) Las vidas de los más excelentes arquitectos pintores y escultores italianos desde Cimabue a nuestros tiempos (Antología), (s. XVI-XVII), Madrid: Tecnos, 1998 